\title{
Nuclear replacement during mating in Armillaria ostoyae (Basidiomycotina)
}

\author{
David M. Rizzo'† and Georgiana May² \\ Author for correspondence: David M. Rizzo. Tel: +1 608231 9214. Fax: +1 6082319592. \\ e-mail : dmrizzo@facstaff.wisc.edu
}

Departments of Plant Pathology ${ }^{1}$ and Plant Biology2, University of Minnesota, St Paul 55108, USA

\begin{abstract}
In Armillaria ostoyae diploid mycelium may mate with haploid mycelium in a process analogous to dikaryon-monokaryon matings in other basidiomycete fungi. Cultural characteristics and molecular markers were used to study inheritance of nuclear and mitochondrial DNA in four diploid-haploid matings of A. ostoyae. When haploids are mated with diploids, morphological changes from fluffy to flat in the haploid thallus can be used to follow mating progress. Progeny originating from the haploid thallus had mitochondrial haplotypes identical to the haploid parent. Progeny with fluffy colony morphology (putatively haploid) all had nuclear haplotypes identical to the haploid parent. Flat progeny (putatively diploid) had nuclear haplotypes either the same as the diploid parent or a combination of all of the diploid and haploid parent nuclear markers. Diploid-diploid pairings between the parents and flat progeny resulted in somatic incompatibility between genetically unlike diploids and demonstrated that somatic incompatibility is a reliable indicator of nuclear, but not mitochondrial, condition. The data suggest that nuclei of the diploid parent, but not mitochondria, migrate into the haploid thallus and eventually displace the haploid nuclei. In some instances, stable $2 \mathbf{N}+\mathbf{N}$ dikaryons were maintained.
\end{abstract}

Keywords: Armillaria ostoyae, nuclear replacement, nuclear migration, mating

\section{INTRODUCTION}

Mating systems in basidiomycetous fungi allow for continual production of new genetic associations prior to meiosis. In most of these fungi, two haploid, monokaryotic colonies with compatible mating factors mate to form a secondary mycelium with binucleate cells, known as a dikaryon. The presence of a clamp connection, an appendage found at septa between hyphal cells, is an identifying feature of dikaryons. Dikaryons may continue to mate with monokaryons by donating one nucleus to the monokaryon via nuclear migration. The process of dikaryon-monokaryon matings has been studied in some detail for many basidiomycetes (Buller, 1931; Swiezynski \& Day, 1960; Ellingboe \& Raper, 1962; Aylmore \& Todd, 1984; Nguyen \& Niederpruem, 1984; Coates \&

†Present address: One Gifford Pinchot Drive, Center for Forest Mycology Research, Forest Products Laboratory, Madison, WI 53705-2398, USA.

Abbreviations: mtDNA, mitochondrial DNA; rDNA, ribosomal DNA; RFLP, restriction fragment length polymorphism; RAPD, random amplified polymorphic DNA.
Rayner, 1985; May \& Taylor, 1988). In contrast to most basidiomycetes, the secondary mycelium of the agaric Armillaria is uninucleate and diploid rather than dikaryotic (Korhonen \& Hintikka, 1974; Guillaumin et al., 1991). Armillaria does retain the ability, however, for diploid mycelia to mate with compatible haploid mycelia to produce new diploid cells (Korhonen, 1978; Anderson \& Ullrich, 1982; Guillaumin, 1986; Guillaumin et al., 1991; Rizzo \& Harrington, 1992). The genetic consequences of diploid-haploid matings in Armillaria are not well understood.

The secondary, diploid mycelium of Armillaria does not possess clamp connections. Therefore, demonstration of successful diploid-haploid matings with Armillaria has relied on differences in colony morphology between diploid cultures (flat, crustose mycelium with sparse aerial mycelium) and haploid cultures (white with fluffy aerial mycelium) (Hintikka, 1973; Korhonen, 1978). Changes in a haploid thallus from a fluffy to flat colony morphology following mating with a diploid strain suggest nuclear migration and conversion of the haploid thallus to a diploid. In a recent study, the use of isozyme markers 
confirmed a genetic basis for the formation of a diploid in diploid-haploid matings with Armillaria ostoyae (Rizzo \&: Harrington, 1992).

Two hypotheses have been suggested for the genetic outcome of diploid-haploid matings in Armillaria. Diploids of Armillaria are considered to be very stable (Anderson \& Ullrich, 1982), leading several authors to propose that the diploid nucleus migrates into the haploid mycelium and eventually displaces the haploid nucleus (Anderson \& Ullrich, 1982; Guillaumin, 1986; Ullrich \&. Anderson, 1988; Guillaumin et al., 1991; Rizzo \&. Harrington, 1992). Alternatively, chromosomes of the diploid and haploid nuclei might reassort during vegetative stages of mating and produce new diploid nuclear: genotypes (Guillaumin, 1986). The breakdown of diploid nuclei into haploid complements has been observed during basidiome (mushroom) formation in Armillaria (Tommerup \& Broadbent, 1975; Korhonen, 1980; Guillaumin, 1986), leading to speculation that such events; may also occur in vegetative mycelia.

To differentiate between these two possible genetic: outcomes in $A$. ostoyae, we used molecular markers (nuclear and mtDNA) to follow genetic exchange in diploid-haploid matings. Mitochondria do not migrate: with nuclei following hyphal fusion in basidiomycetes (Casselton \& Economou, 1985; Hintz et al., 1988; May \& Taylor, 1988), allowing us to use mtDNA to distinguish between migration by the diploid nucleus and invasive growth by diploid hyphae into the haploid thallus. Nuclear markers were used to determine if genetic reassortment was taking place between diploid and haploid nuclei. In addition, somatic and sexual compatibility were used as a confirmation of nuclear condition. The results of these experiments support the hypothesis that the diploid nucleus migrates into the haploid thallus and eventually replaces the haploid nucleus.

\section{METHODS}

Strains. A number of diploid and haploid strains of $A$. ostoyae were screened for characters such as distinctive culture morphology, mating competence and presence of DNA polymorphisms. Two diploid and two haploid strains were chosen for the mating experiments. For the experiments we used naturally derived strains of $A$. ostoyae. Diploid strains B635 (DIP 1) and B684 (DIP 2) were isolated from mycelia found on Acer pensylvanicum and Picea rubens, respectively. Haploid strains B280 (HAP 1) and B430 (HAP 2) were single-spore strains obtained from spore showers of basidiomes. Strain numbers refer to the culture collection of T. C. Harrington, Iowa State Univérsity, Ames, USA.

\section{Diploid-haploid matings}

The two diploid strains were paired individually with each of the haploid strains. The matings were conducted on $1 \%(\mathrm{w} / \mathrm{v})$ malt extract agar (MEA; $10 \mathrm{~g}$ Difco malt extract, $15 \mathrm{~g}$ Difco agar per litre water) by plating inocula from one-week-old colonies $5 \mathrm{~mm}$ apart and incubating at room temperature $\left(20-25^{\circ} \mathrm{C}\right)$ with laboratory lighting. Each mating was replicated five times. At 20, 30 and $40 \mathrm{~d}$ subcultures were taken from the side of the haploid strain (HAP 1 or HAP 2). From each replicate plate, $3 \mathrm{~mm}$ diam plugs were taken 2,10 and $15-25 \mathrm{~mm}$ (the advancing margin) from the confrontation zone between the paired strains. As a control, one subculture plug was taken $2 \mathrm{~mm}$ from the confrontation zone on the diploid strain side. Subculture plugs were transferred to MEA and incubated under laboratory conditions for 7-10 d. Subcultures were evaluated for colony morphology: fluffy (putatively haploid), flat (putatively diploid), or with fluffy and flat sectors.

First vegetative generation progeny (Fig. 1). Subculturing resulted in the mass transfer of hyphae from the original pairing plates. To accurately assess nuclear migration into the haploid thallus and avoid sampling a mixture of hyphae from the diploid and haploid parents, single hyphal tip cells were removed from subcultures and used to initiate colonies. Using $\times 40$ magnification, hyphal tips were excised from each of the subcultures listed above. Hyphal tips were removed without regard to subculture morphology. However, hyphal tips were selected on the basis of ease of excision, which could result in a bias for fast-growing hyphal tips. Transfer plates were examined microscopically to confirm that only one hyphal tip had been transferred. A minimum of 25 hyphal tips were taken for each sampling time and sampling distance. Hyphal tips were transferred to MEA, incubated as above for 14-16 d and scored for colony morphology. Hyphal tip progeny were stored on MEA at $4{ }^{\circ} \mathrm{C}$.

Second vegetative generation progeny (Fig. 1). Progeny were subcultured at three month intervals by taking plugs of hyphae from the advancing margin and transferring to MEA plates. After six months (two transfers), a subset of progeny with flat

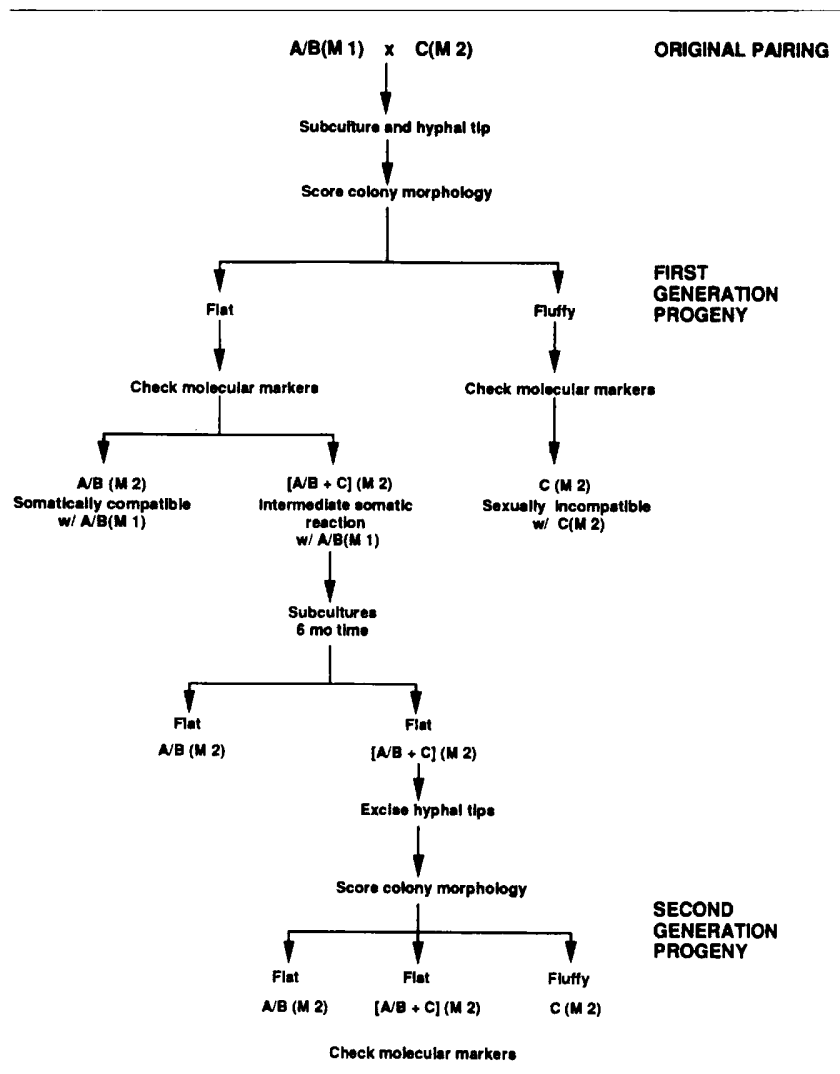

Fig. 1. Flow chart summary of experimental design and results of diploid-haploid matings. $A / B$ and $C$ represent diploid and haploid nuclei, respectively. $M 1$ and $M 2$ represent different mitochondrial haplotypes. 
morphology were chosen (see Results) and hyphal tips transferred again to yield a second generation of progeny.

Haploid-haploid matings. A. ostoyae has a heterothallic, bifactoral mating system (Hintikka, 1973). To detect possible recombination of mating factors, fluffy hyphal tip progeny (putatively haploid) were paired with the haploid parents, HAP 1 and HAP 2. HAP 1 and HAP 2 were also paired with each other to confirm sexual compatibility. Matings were made and scored as described in Harrington et al. (1992).

Somatic incompatibility pairings. Pairings were made between all progeny with a flat colony morphology (putatively diploid) and parents DIP 1 and DIP 2 to determine if somatic incompatibility was a useful indicator of nuclear and mitochondrial condition. Pairings were made as in Harrington et al. (1992). Mycelia that gew together to form a single homogeneous colony with no dark lines, sparse zones or other barrage zones were considered to be somatically compatible (Harrington $e t$ al., 1992) (see Fig. 4).

DNA extraction. Fluffy and flat progeny from matings DIP $1 \times$ HAP 2 ( 34 progeny) and DIP $2 \times$ HAP 1 ( 34 progeny) were grown in liquid medium for DNA extraction. Plugs of mycelium from MEA plates were inoculated into $25-30 \mathrm{ml}$ liquid malt yeast extract medium (MYE; $20 \mathrm{~g}$ malt extract, $2 \mathrm{~g}$ yeast extract per litre water) in $90 \mathrm{~mm}$ plastic Petri dishes and incubated in still culture at $20-25^{\circ} \mathrm{C}$ for $3-4$ weeks. Mycelia were vacuumfiltered, frozen in liquid nitrogen, lyophilized and stored at $-80^{\circ} \mathrm{C}$ until needed.

DNA was extracted from lyophilized tissue using a modification of the miniprep procedure of Davis et al. (1980) (P. T. Gieser, personal communication). Approximately $100 \mathrm{mg}$ finely ground, lyophilized mycelia was added to a microfuge tube and $500 \mu$ l extraction buffer added. Extraction buffer was prepared by mixing $50 \mathrm{mM}$ EDTA ( $\mathrm{pH} 8.0$ ), $500 \mathrm{mM} \mathrm{NaCl}, 100 \mathrm{mM}$ Tris (pH 8.0), $1.25 \%(\mathrm{w} / \mathrm{v}) \mathrm{SDS}$, and $10 \mathrm{mM} \beta$-mercaptoethanol. Following incubation in a $65^{\circ} \mathrm{C}$ water bath for $15 \mathrm{~min}$, $200 \mu \mathrm{l} 5 \mathrm{M}$ acetate ( $\mathrm{pH} 5.2$ ) was added to each tube and the tubes were placed on ice for $20 \mathrm{~min}$. The tubes were centrifuged for 15 min at 14000 r.p.m. and the supernatant was then transferred to new tubes. 2-Propanol $(0 \cdot 5-0 \cdot 6 \mathrm{vol}$. $)$ was added to each tube and the tubes centrifuged for $15 \mathrm{~min}$. Following centrifugation, the supernatant was discarded and the pellet resuspended in $50 \mathrm{mM}$ Tris $/ 10 \mathrm{mM}$ EDTA. This mixture was incubated at $37^{\circ} \mathrm{C}$ for $60 \mathrm{~min}$ with $1 \mu \mathrm{l} \mathrm{RNase}\left(\right.$ Sigma, $5 \mu \mathrm{g} \mathrm{ml}^{-1}$ ). Insoluble debris was removed by centrifugation at 10000 r.p.m. for $3 \mathrm{~min}$ and the supernatant transferred to new tubes. DNA was precipitated in $600 \mu \mathrm{l}$ cold absolute ethanol and $100 \mu \mathrm{l} 3 \mathrm{M}$ sodium acetate. After centrifugation at 14000 r.p.m. for $10 \mathrm{~min}$, the supernatant was discarded, and the pellet was washed with cold $70 \%(\mathrm{v} / \mathrm{v})$ ethanol and dried for $5 \mathrm{~min}$ in a speed vac (Savant Instruments). DNA was resuspended in $100 \mu \mathrm{l}$ TE (10 $\mathrm{mM}$ Tris $/ 1 \mathrm{mM}$ EDTA) and stored at $-20^{\circ} \mathrm{C}$.

Restriction fragment length polymorphism (RFLP) analysis. Samples of miniprep DNA were digested with the restriction enzymes HindIII, Bam HI or PstI. Digests were for $8-12 \mathrm{~h}$ at $37^{\circ} \mathrm{C}$ according to the manufacturer's instructions, except that spermidine was added to each reaction to a final concentration of $5 \mathrm{mM}$. Electrophoresis was carried out in $0.8 \%$ agarose gels run at $1.5 \mathrm{~V} \mathrm{~cm}^{-1}$ for $16 \mathrm{~h}$ in $1 \times \mathrm{TAE}$ buffer $(40 \mathrm{mM}$ Tris/acetate, $1 \mathrm{mM}$ EDTA). DNA fragments were transferred to nylon membranes (Hybond-N, Amersham) by standard methods (Sambrook et al., 1989).

RFLP probes used in this study were kindly provided by M. L. Smith and J. B. Anderson (Erindale College, University of Toronto, Mississauga, Ontario, Canada). Mitochondrial haplo- types were determined by hybridization with purified $A$. ostoyae mtDNA (Smith \& Anderson, 1989). Two RFLP probes were used to follow nuclear migration. Probe pJA-1 was a pUC9 plasmid with a rDNA fragment from $A$. ostoyae containing the 26S rRNA gene (Anderson et al., 1989). Probe SpVII p-8 was a cloned copy of a dispersed repetitive sequence from Armillaria gallica (Smith et al., 1992). Probes were random prime labelled and hybridized to the blots for $2 \mathrm{~h}$ using QuickHyb hybridization solution following the manufacturer's instructions (Stratagene Cloning Systems). Blots were exposed on X-ray film for $2 \mathrm{~h}-6 \mathrm{~d}$.

Fig. 3 represents examples of mitochondrial and nuclear haplotypes for mating DIP $1 \times$ HAP 2 . The mtDNA probe hybridized to 13-15 HindIII restriction fragments between 3 and $14 \mathrm{~kb}$ (Fig. 3a). Each parent strain had a unique mitochondrial haplotype. Three polymorphisms allowed us to distinguish between DIP 1 and HAP 2 mitochondrial haplotypes (Fig. 3a), and two polymorphisms were detected between DIP 2 and HAP 1 . Nuclear haplotypes were based on the banding patterns obtained with two RFLP probes and three RAPD primers. rDNA probe $\mathrm{pJA}-1$ hybridized to two fragments (approx. 4.5 and $5 \mathrm{~kb}$ ) in the diploid parents and one fragment in each of the haploid parents (HAP 1, 4.5 kb and HAP 2, $4.8 \mathrm{~kb}$ ) on the HindIII blots (Fig. $3 \mathrm{~b}$ ). The dispersed repetitive probe SpVII p- 8 hybridized to 10 or 11 HindIII restriction fragments, with three or four polymorphisms distinguishing the different strains (Fig. 3c). pJA-1 and SpVII p-8 were also hybridized to PstI and Bam HI digested DNA, respectively, and these confirmed the results of the HindIII hybridizations.

Random amplified polymorphic DNA (RAPD) analysis. RAPD amplification conditions were modified from the protocol of Williams $e$ t al. (1990). A cocktail was prepared with $1 \times \mathrm{RAPD}$ buffer (100 mM Tris, pH 8.0/500 mM KCl), $2 \mathrm{mM} \mathrm{MgCl}$, $0.5 \%$ Tween, $0.4 \mathrm{mM}$ spermidine, $1 \mu \mathrm{M}$ dNTPs, $15 \mathrm{ng}$ primer (Kit M, Operon Technologies), 2-5 ng template DNA and $0.75 \mathrm{U}$ Taq polymerase (Promega) per reaction. RAPD products were amplified in a Perkin-Elmer thermocycler programmed for one cycle of $5 \mathrm{~min}$ at $94^{\circ} \mathrm{C}, 45$ cycles of $1 \mathrm{~min}$ at $94^{\circ} \mathrm{C}, 1 \mathrm{~min}$ at $36{ }^{\circ} \mathrm{C}$ and $2 \mathrm{~min}$ at $72{ }^{\circ} \mathrm{C}$, and one cycle of $10 \mathrm{~min}$ at $72{ }^{\circ} \mathrm{C}$ with the fastest possible transition times between temperatures. Amplification products were electrophoresed in $1.4 \%(\mathrm{w} / \mathrm{v})$ agarose gels in $1 \times \mathrm{TAE}$ and stained with ethidium bromide.

Twenty primers from Operon Kit $M$ were screened for polymorphisms. Three primers (M1, M4 and M5) had unique bands for both the diploid and haploid parents (Fig. 3) and were consistently reproducible. Because RAPD bands behave as dominant markers (Williams et al., 1990), we scored bands uniquely represented in the diploid or haploid parents as present or absent in the progeny. Fig. 3(d) is an example of banding patterns obtained with primer M5 for mating DIP $1 \times$ HAP 2 . Bands unique to the haploid parents were excellent markers for the presence of the haploid parent nucleus in the progeny. We did not confirm whether bands unique to the diploid parents were heterozygous or homozygous. We assumed only that the absence or presence of a single unique band from a diploid parent in the progeny indicated migration of that marker locus but not of the entire diploid nucleus. By taking into account all of the RFLP and RAPD data, we are confident of our ability to detect nuclear migration.

Nuclear staining. The number of nuclei per cell in the parent strains and twelve progeny was confirmed by staining with DAPI (4',6-diamidino-2-phenylindole). Mycelia from oneweek-old cultures (grown on MEA) was directly stained with DAPI without fixation (Heath, 1987). Observation of nuclei was made with a Zeiss epifluorescence microscope. 


\section{RESULTS}

A flow chart summary of experiments and results is presented in Fig. 1. Morphological observations of subcultures and first generation hyphal tip progeny from diploid-haploid pairings were made following the original pairings. The initial examinations of molecular markers and somatic incompatibility pairings using first generation progeny were done simultaneously and independently.

\section{Culture morphology}

Nuclear migration and conversion of the haploid thallus to a diploid state are marked by changes in colony morphology of haploid mycelia from fluffy to flat. After pairing for 20,30 or $40 \mathrm{~d}$ with DIP 1 or DIP 2, subcultures taken from the thallus of HAP 1 or HAP 2 were either

Table 1. Colony morphology of second generation progeny

\begin{tabular}{|cccc|}
\hline Mating & \multirow{2}{*}{$\begin{array}{c}\text { No. of } \\
\text { progeny* }\end{array}$} & Colony morphology (\%) \\
\cline { 3 - 4 } & & Fluffy & Flat \\
\hline DIP 1 & & & \\
DIP HAP 1 & 17 & 12 & 88 \\
DIP 2 $\times$ HAP 2 & 57 & 12 & 88 \\
DIP 2 $\times$ HAP 2 & 93 & 2 & 98 \\
& 21 & 5 & 95 \\
\hline
\end{tabular}

* Total number of second generation hyphal tip progeny recovered from first generation progeny of each mating.

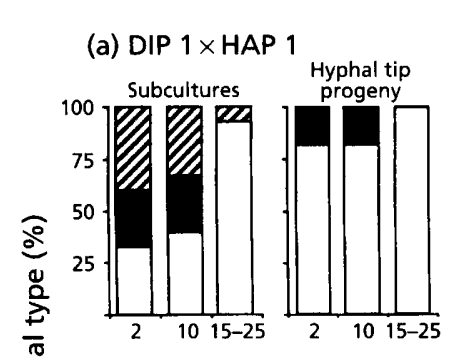

(b) DIP $1 \times$ HAP 2
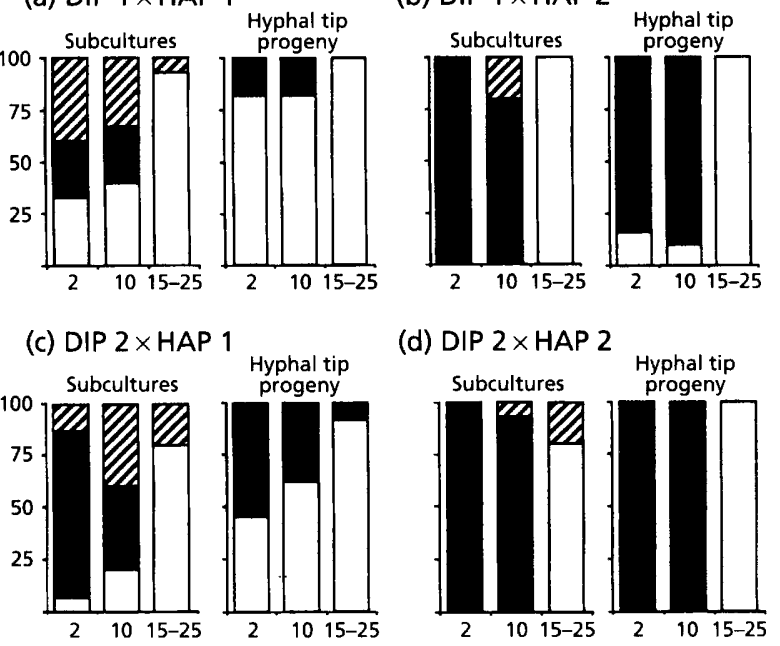

(d) DIP $2 \times$ HAP 2

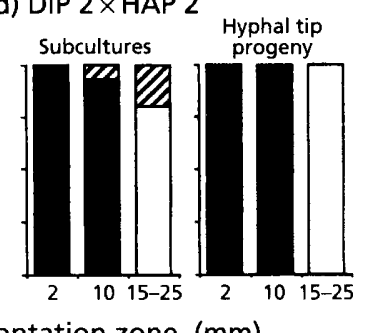

Distance from confrontation zone $(\mathrm{mm})$

Fig. 2. Morphology of subcultures and hyphal tip progeny taken from haploids HAP 1 and HAP 2 following mating with diploids DIP 1 and DIP 2. Colony morphologies: $\square$, fluffy; flat; $\square$, sectored.

fluffy, flat, or fluffy with flat sectors (Fig. 2). The number of flat subcultures remained constant over 20,30 and $40 \mathrm{~d}$, indicating that $20 \mathrm{~d}$ was sufficient time to allow for nuclear migration.

In all of the matings, most of the subcultures taken $2 \mathrm{~mm}$ and $10 \mathrm{~mm}$ from the confrontation zone resulted in flat or sectored colonies (Fig. 2). The majority of subcultures

Table 2. Colony morphology, and mitochondrial and nuclear haplotypes of selected first generation progeny excised from subcultures of diploid-haploid matings

\begin{tabular}{|c|c|c|c|c|c|c|}
\hline \multirow[t]{2}{*}{ Mating* } & \multirow[t]{2}{*}{$\begin{array}{c}\text { Colony } \\
\text { morphology }\end{array}$} & \multicolumn{2}{|c|}{$\begin{array}{l}\text { Mitochondrial } \\
\text { haplotype } \dagger\end{array}$} & \multicolumn{3}{|c|}{$\begin{array}{c}\text { Nuclear } \\
\text { haplotype } \neq\end{array}$} \\
\hline & & Haploid & Diploid & Haploid & Diploid & Mixed \\
\hline \multirow[t]{2}{*}{ DIP $1 \times$ HAP 2} & Fluffy & 12 & 0 & 12 & 0 & 0 \\
\hline & Flat & 17 & 0 & 0 & 10 & 7 \\
\hline Control & Flat & 0 & 2 & 0 & 2 & 0 \\
\hline \multirow[t]{2}{*}{ DIP $2 \times$ HAP 1} & Fluffy & 11 & 0 & 11 & 0 & 0 \\
\hline & Flat & 16 & 0 & 0 & 0 & 16 \\
\hline Control & Flat & 0 & 2 & 0 & 2 & 0 \\
\hline
\end{tabular}

* Control hyphal tip progeny were excised from subcultures taken from the diploid parent. Data from eight progeny, representing invasive growth of diploid hyphae into the haploid thallus, are not included in the table. A complete data set is available on request from the authors.

† Numbers represent total number of progeny tested. Mitochondrial haplotype based on probe mt- 482 . Haplotypes were identical to either those of haploids HAP 1 or HAP 2, or diploids DIP 1 or DIP 2.

$\ddagger$ Nuclear haplotypes based on RFLP probes pJA-1 and SpVII p8, and RAPD markers M1, M4 and M5. Haploid haplotypes were identical to either HAP 1 or HAP 2. Diploid haplotypes were identical to either DIP 1 or DIP 2. Mixed haplotypes had all bands of both haploid and diploid parents. 
taken at the advancing margin $(15-25 \mathrm{~mm}$ from the confrontation zone) of the haploid thallus had a fluffy colony morphology (Fig. 2). Samples from the advancing margin yielded $10-20 \%$ sectored colonies from three of the crosses, but no completely flat subcultures. All 60 control subcultures taken at $2 \mathrm{~mm}$ from the confrontation zone on the diploid parent side had a flat colony morphology.

Hyphal tips excised from HAP 1 subcultures resulted in mostly fluffy colonies regardless of whether the hyphal tips were from fluffy or flat subcultures, or flat sectors of predominantly fluffy subcultures (Fig. 2a, c). Hyphal tips excised from HAP 2 subcultures taken at $2 \mathrm{~mm}$ and $10 \mathrm{~mm}$ yielded mostly flat colonies (Fig. 2b, d). All hyphal tips taken from subcultures at $15-25 \mathrm{~mm}$ resulted in fluffy colonies, except in mating DIP $2 \times$ HAP 1 (Fig. 2c). In this mating, six flat hyphal tip progeny were recovered from 15-25 mm subcultures. A small percentage $(<10 \%)$ of hyphal tips did not grow. All hyphal tips excised from control subcultures resulted in flat colonies. Sectoring was not observed in hyphal tip progeny.

At three and six months, all progeny were transferred to fresh MEA plates. A second generation of progeny was obtained by excising 15 hyphal tips from each of 23 flat first generation progeny which had given intermediate reactions in the somatic incompatibility pairings (see below). Approximately $40 \%$ of the 345 hyphal tips did not grow when transferred, but $88-98 \%$ of the hyphal tips that did grow had a flat colony morphology (Table 1 ). Fluffy morphology was observed in some of the second generation progeny from each of the four matings (Table 1).

\section{Haploid-haploid matings}

All matings between fluffy progeny (first and second generation) and related haploid parents, HAP 1 or HAP 2 [e.g. (DIP $1 \times$ HAP 2) fluffy progeny $\times$ HAP 2], resulted in flufy subcultures (data not shown). This result would be expected if the progeny and the haploid parents were identical at the two mating factors. Matings made between progeny and the non-related haploid parent resulted in subcultures with a flat morphology indicating successful mating. Haploid parents HAP 1 and HAP 2 were sexually compatible.

\section{Inheritance of molecular markers}

All fluffy first generation progeny had mitochondrial and nuclear haplotypes identical to their haploid parent (HAP 1 or HAP 2) (Table 2). The majority of flat progeny (33 of 41 total) had mitochondrial haplotypes identical to their haploid parent (Table 2). No recombinant or mixed mitochondrial haplotypes were observed. Eight flat first generation progeny had mitochondrial and nuclear haplotypes identical to their diploid parent (DIP 1 and DIP 2). These hyphal tip progeny were excised from subcultures taken $2 \mathrm{~mm}$ from the confrontation zone and probably represented samples of invasive growth of diploid hyphae into the haploid thallus, rather than nuclear migration.

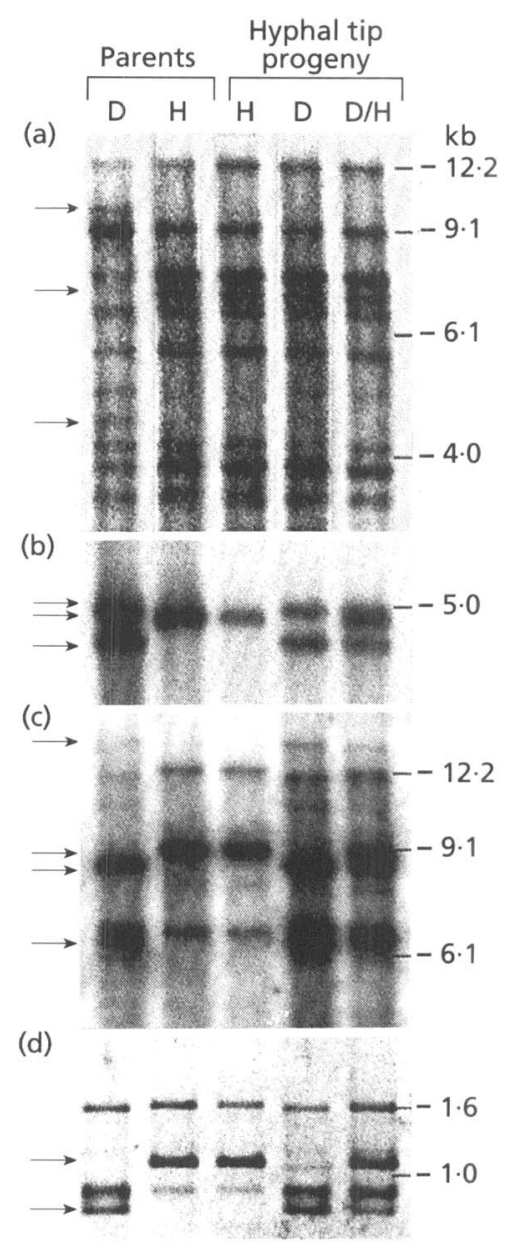

Fig. 3. Examples of mitochondrial and nuclear haplotypes from mating $A$. ostoyae strains DIP $1 \times$ HAP 2 . Lanes 1 and 2 are the diploid $(D)$ and haploid $(H)$ parents and lanes 3-5 are hyphal tip progeny representing haploid, diploid and mixed diploid/haploid $(\mathrm{D} / \mathrm{H})$ genotypes. Hindlil-digested genomic DNA was probed with (a) mtDNA, (b) rDNA, and (c) a dispersed repetitive clone. (d) DNA amplified by RAPD primer M5. Arrows indicate polymorphisms used to distinguish haplotypes. Images from autoradiographs $(a, b$ and $c)$ or ethidium bromide stained gels (d) were digitized using a standard CCD camera (UVP). The figure was prepared using the computer program PHОTOSHOP 2.5 (Adobe Systems). The image of (d) was reversed to allow background continuity with the remainder of the figure.

Flat progeny with mitochondrial haplotypes identical to their haploid parent exhibited two classes of nuclear haplotypes (Fig. 3). The first class, putatively $2 \mathrm{~N}+\mathrm{N}$, demonstrated the presence of all of the bands of the haploid parent and all of the bands of the diploid parent. The second class had all of the markers of the diploid parent, but none of the haploid markers. In either class, no new combinations of bands were observed for the RFLP or RAPD markers (Fig. 3 ). In the DIP $1 \times$ HAP 2 mating, 17 flat progeny had the mitochondrial haplotype of HAP 2 ; of these, ten had nuclear haplotypes identical to DIP 1 and seven had mixed nuclear haplotypes (Table 2). In the DIP $2 \times$ HAP 1 mating, all 16 progeny with the mitochondrial haplotype of HAP 1 had mixed nuclear haplo- 
Table 3. Results of somatic incompatibility pairings between diploid parents (DIP 1 or DIP 2) and first generation progeny with flat colony morphology

\begin{tabular}{|c|c|c|c|}
\hline \multirow[t]{2}{*}{ Mating* } & \multicolumn{3}{|c|}{ Pairing morphology $(\%) \dagger$} \\
\hline & Compatible & Intermec & mpatible \\
\hline $\operatorname{DIP} 1 \times \operatorname{HAP} 1(n=13)$ & 31 & 69 & 0 \\
\hline DIP $1 \times$ HAP $2(n=39)$ & 49 & 51 & 0 \\
\hline DIP $2 \times \operatorname{HAP} 1(n=37)$ & 19 & 81 & 0 \\
\hline DIP $2 \times$ HAP $2(n=37)$ & 68 & 32 & 0 \\
\hline
\end{tabular}

* $n$ equals the total number of first generation progeny paired with their diploid parent. Data from 20,30 and $40 \mathrm{~d}$ were combined.

t See text and Fig. 4 for description of pairing morphology.

types with all markers of both DIP 2 and HAP 1 (Table 2). Control progeny (taken from diploid parents rather than haploid parents in original matings) had mitochondrial and nuclear haplotypes identical to the diploid parents (Table 2).

To test the stability of nuclear haplotypes over time, second generation hyphal tip progeny were obtained from first generation progeny with mixed nuclear haplotypes. The molecular markers were assayed again. Mitochondrial haplotypes were stable in all second generation progeny. In mating DIP $1 \times$ HAP 2 , ten second generation progeny with flat morphology were screened; two of them had lost all of the nuclear markers of HAP 2. Three second generation progeny with fluffy morphology from matirg DIP $1 \times$ HAP 2 retained the HAP 2 nuclear haplotype and no diploid markers were detected. In the mating DIP $2 \times$ HAP 1 , all eight second generation progeriy maintained the mixed nuclear haplotype observed above.

\section{Number of nuclei per cell}

The number of nuclei per cell in the four parent strains and twelve progeny was observed by staining with DAPI. Only one nucleus per cell was observed in the diploid and haploid parents. Two progeny with the nuclear haplotype of DIP 1 (from DIP $1 \times$ HAP 2) were also monokaryotic. Ten progeny with mixed nuclear haplotypes (two from DIP $1 \times$ HAP 2 and eight from DIP $2 \times$ HAP 1 ) were found to be binucleate (i.e. two nuclei per cell). This observation supports the hypothesis that mycelia wita mixed nuclear haplotypes have a nuclear state of $2 \mathrm{~N}+\mathrm{N}$.

\section{Somatic incompatibility pairings}

The molecular and cytological data suggested two classes of hyphal tip progeny with the flat morphology characteristic of diploidy : putatively $2 \mathrm{~N}+\mathrm{N}$ binucleate cells and $2 \mathrm{~N}$ diploid cells. To test this hypothesis further, we paired flat first and second generation progeny with diploid parents, DIP 1 or DIP 2, and we paired these same progeny with each other in all combinations. If no chromosomal reassortment had occurred in the original matings, we expected that the $2 \mathrm{~N}$ class of progeny would be somatically compatible with their parent diploid. We expected that the $2 \mathrm{~N}+\mathrm{N}$ class would not be compatible with the parent diploid due to the presence of the additional haploid nucleus. Further, without reassortment, the $2 \mathrm{~N}+\mathrm{N}$ progeny from one mating should not exhibit somatic incompatibility when paired with each other. The pairings were conducted with progeny from all four matings. The two classes of flat progeny were verified by somatic incompatibility tests as presented below.

A total of 126 first generation progeny were paired with the diploid parents, DIP 1 or DIP 2 (Table 3). Pairings were scored as compatible if paired mycelia grew together and formed a single colony with no obvious confrontation zones (Fig. 4a). Incompatible pairings, such as between DIP 1 and DIP 2, resulted in the formation of a distinct sparse zone at the confrontation of the colonies (Fig. 4c). Often a dark line formed within the agar (seen from below the plate) between incompatible mycelia. A reaction intermediate to the compatible and incompatible reactions was observed in many of the pairings (Fig. 4b). No extensive sparse zones or dark lines were formed in the intermediate reaction; however, the paired mycelia did not grow completely together to form a single colony.

The majority of progeny from matings DIP $1 \times$ HAP 1 and DIP $2 \times$ HAP 1 had an intermediate reaction when paired with their diploid parent (DIP 1 and DIP 2, respectively) (Table 3 ). Approximately half of the progeny from DIP $1 \times$ HAP 2 had intermediate reactions with DIP 1 (Table 3). These pairings were difficult to read because several of the previously flat progeny sectored into small areas of fluffy aerial mycelium indicating breakdown to a haploid state. Most of the progeny from mating DIP $2 \times$ HAP 2 were compatible with DIP 2 (Table 3). All first generation progeny gave incompatible reactions when paired with the diploid strain that was not its parent.

For the crosses DIP $1 \times$ HAP 1 and DIP $2 \times$ HAP 2 where molecular markers were not scored, two classes of progeny with flat morphology were apparent as described above. These progeny either gave an intermediate reaction or were compatible with the parent diploid. Within the 

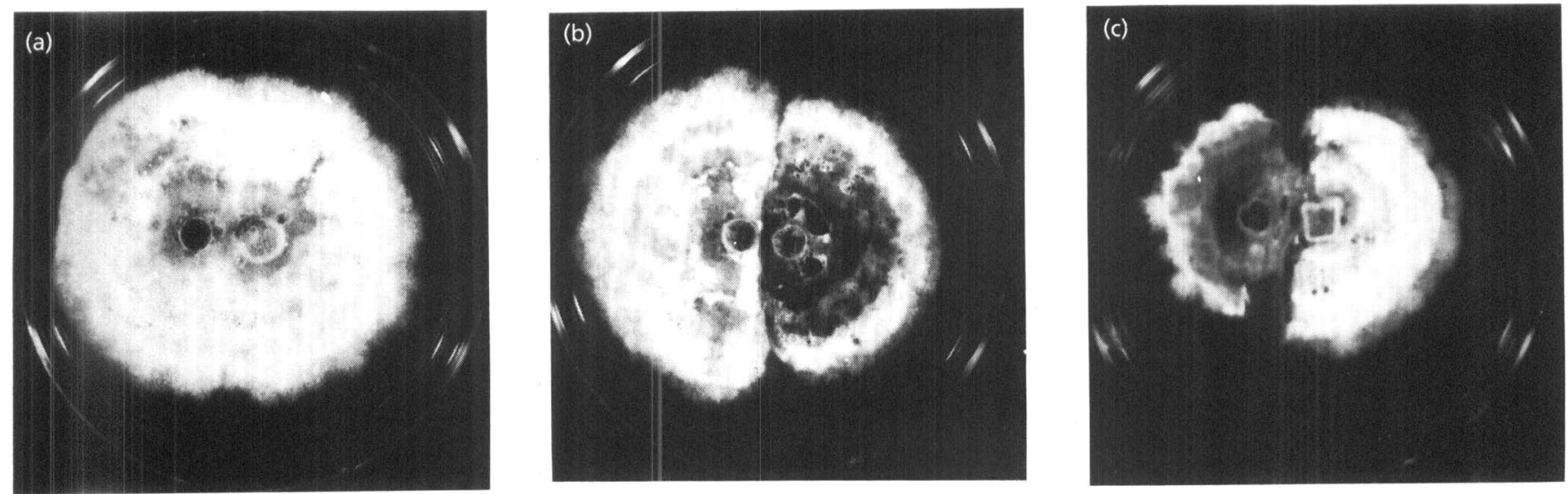

Fig. 4. Diploid-diploid pairings with $A$. ostoyae demonstrating different levels of somatic incompatibility. (a) Completely compatible interaction, (b) intermediate reaction, (c) incompatible reaction showing sparse zone and pigment formation.

progeny from one mating, those progeny giving an intermediate reaction with the parent diploid were paired with each other and they were all somatically compatible. Those progeny that were compatible with the diploid parent were also somatically compatible with each other.

Correlation of molecular markers and somatic incompatibility. In the matings DIP $1 \times$ HAP 2 and DIP $2 \times$ HAP 1 in which molecular markers were analysed, progeny with only the nuclear markers of their diploid parents gave compatible somatic reactions when paired with those parents. In mating DIP $1 \times$ HAP 2, all ten progeny with nuclear haplotypes identical to DIP 1 were somatically compatible with strain DIP 1. Progeny with mixed nuclear haplotypes (putatively $2 \mathrm{~N}+\mathrm{N}$ ) gave intermediate somatic reactions when paired with their diploid parents. In matings DIP $1 \times$ HAP 2 and DIP $2 \times$ HAP 1 , all progeny ( 7 and 16 progeny, respectively) with mixed nuclear haplotypes gave intermediate reactions with the diploid parents. Paired among themselves, putative $2 \mathrm{~N}$ and putative $2 \mathrm{~N}+\mathrm{N}$ progeny from a single cross gave compatible reactions with progeny of identical nuclear haplotype. When mycelia with distinctly different nuclear haplotypes (e.g. between progeny with different diploid parents) were paired, incompatible reactions always resulted. These results suggest that somatic incompatibility is a reliable indicator of nuclear condition. The results of these pairings further demonstrated that only two classes of progeny with flat morphology resulted from diploid $\times$ haploid matings.

Somatic incompatibility did not distinguish mitochondrial condition. In mating DIP $1 \times$ HAP 2 , progeny with nuclear haplotypes identical to DIP 1 were somatically compatible with DIP 1 regardless of whether mtDNA from DIP 1 or HAP 2 was present in the cytoplasm. In mating DIP $2 \times$ HAP 1 , no progeny were identified with the nuclear haplotype of DIP 2 and the mtDNA of HAP 1.

Stability of the $\mathbf{2 N}+\mathbf{N}$ condition. Somatic incompatibility pairings were repeated following subculturing (mass transfer of hyphae) of putative $2 \mathrm{~N}+\mathrm{N}$ first generation progeny from all four original matings. These progeny originally had given intermediate reactions when paired with their respective diploid parent. Approximately $50 \%$ of the subcultures gave compatible reactions when paired again with their diploid parent. The exception was mating DIP $2 \times$ HAP 1 , in which all progeny following subculturing maintained the intermediate reaction with DIP 2.

As noted previously, single hyphal tip cells were excised from putative $2 \mathrm{~N}+\mathrm{N}$ first generation progeny to yield a second generation of progeny. Second generation progeny with flat morphology also exhibited either compatible or intermediate somatic reactions when paired with their original diploid parent, DIP 1 or DIP 2 . In mating DIP $1 \times$ HAP 1 , four of ten second generation progeny were compatible with DIP 1 . In mating DIP $1 \times$ HAP 2, 25 of 38 second generation progeny were compatible with DIP 1. In contrast, all 69 second generation progeny from DIP $2 \times$ HAP 1 gave an intermediate reaction with DIP 2. Two of seven second generation progeny from DIP $2 \times$ HAP 2 were found to be compatible with DIP 2. Paired among themselves, second generation progeny from a single cross were delineated into two somatic incompatibility classes. Progeny that exhibited intermediate somatic reactions with diploid parents were compatible with each other and had intermediate reactions with those progeny that had been compatible with the diploid parents (data not shown). The $2 \mathrm{~N}+\mathrm{N}$ progeny of some crosses were apparently more stable that $2 \mathrm{~N}+\mathrm{N}$ progeny of other crosses.

Pairings were attempted between (DIP $1 \times \mathrm{HAP} 1) \times$ (DIP $1 \times$ HAP 2) and (DIP $2 \times$ HAP 1$) \times($ DIP $2 \times$ HAP 2) progeny. Using first generation progeny, all such pairings were incompatible. Using second generation progeny, compatible reactions were observed between one progeny of (DIP $1 \times$ HAP 1 ) and six progeny of (DIP $1 \times$ HAP 2 ). In these compatible pairings, all progeny had the nuclear haplotype of DIP 1 and the mitochondrial haplotype of their haploid parent. No compatible or intermediate pairings were observed in pairing (DIP $2 \times$ HAP 1$) \times($ DIP $2 \times$ HAP 2$)$ using second generation progeny. 


\section{DISCUSSION}

Our data support the hypothesis that, in diploid-haploid matings of $A$. ostoyae, diploid nuclei replace the nuclei in the original haploid thallus without chromosomal reassortment between diploid and haploid nuclei in vegetative mycelia. This pattern of mating is different than has been found in investigations of dikaryonmonokaryon matings in basidiomycetes with a dikaryotic state, such as Coprinus cinereus and Schizophyllum commune (Swiezynski \& Day, 1960; Ellingboe \& Raper, 1962; Nguyen \& Niederpruem, 1984; May \& Taylor, 1988). In these fungi, new dikaryotic associations are formed following nuclear migration into the monokaryon.

The molecular and cultural evidence (sexual and somatic compatibility) suggest that, following nuclear migration, the recipient thallus is a mosaic of haploid, diploid and binucleate $2 \mathrm{~N}+\mathrm{N}$ cells. When hyphal tips are excised to analyse these cells separately, fluffy $(\mathrm{N})$ and flat $(2 \mathrm{~N}$ and $2 \mathrm{~N}+\mathrm{N}$ ) cultures are obtained. In all outcomes, no progeny were obtained that demonstrated reassortment of haploid and diploid markers. All fluffy progeny recovered were identical to the haploid parents for the molecular markers and the mating factors; no fluffy progeny with markers unique to the diploid parents were detected. Of the flat progeny, only two classes were evident. Recovery of $2 \mathrm{~N}$ cells that were apparently identical to the diploid indicates nuclear replacement. Recovery of binucleate cells indicates an association of diploid and haploid nuclei. The hypothesis that recombination or reassortment of diploid and haploid nuclei occurs after mating is not supported by our data, because cells with some, but not all, of the markers for each nucleus were never recovered, and because somatic incompatibility tests resulted in just two classes of progeny with flat morphology. While our RFLP and RAPD markers were not subject to segregation analysis, changes in nuclear haplotypes over time were always marked by the loss of all diploid parent or haploid parent markers from the $2 \mathrm{~N}+\mathrm{N}$ state. It would seem unlikely that all of our nuclear markers were linked; for example, the probe SpVIIp-8 is known to represent dispersed and repetitive DNA (Smith et al., 1992). These results agree with those obtained by Rizzo \& Harrington (1992) for A. ostoyae in which mixed isozyme phenotypes without recombination were recovered. It is therefore unlikely that the original diploid parents became haploid prior to or during mating and vegetative growth. Diploids of Armillaria have been found to be very stable despite attempts to induce haploidization through mutagenesis and hyphal tip transfers (Anderson \& Ullrich, 1982; Anderson \& Yacoob, 1984).

Presence of diploid or mixed diploid-haploid nuclear haplotypes along with haploid parent mtDNA in hyphal tip progeny originating from the haploid thallus provided definitive evidence of nuclear migration from diploid to haploid mycelia. Mitochondria do not migrate along with nuclei following hyphal fusion in basidiomycete matings (Casselton \& Economou, 1985; Hintz et al., 1988; May \& Taylor, 1988), and this has been previously demonstrated in matings between monokaryons of Armillaria (Smith et al., 1990). Invasive growth of $A$. ostoyae hyphae into the haploid colony was only detected $2 \mathrm{~mm}$ from the confrontation zone in the original mating.

We did find evidence of stable $2 \mathrm{~N}+\mathrm{N}$ dikaryons, confirmed by DAPI staining, in $A$. ostoyae. Transient binucleate $(\mathrm{N}+\mathrm{N})$ stages are known at several places in the life cycle of $A$. ostoyae. At the earliest stages of haploid mating, clamp connections are evident, although the dikaryons are quickly converted to diploids (Korhonen \& Hintikka, 1974; Korhonen, 1983; Larsen et al., 1992). Clamp connections were not evident at any stage of the diploid-haploid interaction in our study. Stability of the binucleate $2 \mathrm{~N}+\mathrm{N}$ state in $A$. ostoyae may be dependent on the genetic background of the individual strains used. For example, the mating DIP $1 \times$ HAP 1 resulted in a number of $2 \mathrm{~N}+\mathrm{N}$ cultures that have been stable for over 12 months. In contrast, matings involving DIP 1 and HAP 2 appeared to break down into their diploid and haploid components readily. However, at least a small percentage of stable $2 \mathrm{~N}+\mathrm{N}$ dikaryons were detected in each of the matings.

Because of the persistence of the $2 \mathrm{~N}+\mathrm{N}$ state in some progeny, the alternative hypothesis of reassortment between nuclei in Armillaria diploid-haploid matings cannot be completely dismissed. During basidiome formation in $A$. ostoyae, diploid cells apparently become dikaryotic (with clamp connections) in the basidial primordia, and return to a diploid state prior to meiosis and basidiospore formation (Tommerup \& Broadbent, 1975; Korhonen, 1980; Guillaumin, 1986). Following a number of diploidhaploid matings with A. ostoyae, Guillaumin (1986) allowed putative diploids to form basidiomes and basidiospores, and recovered a small number of progeny with mating factors of both the diploid and haploid parents. Vegetative mycelia of these strains were not tested for genetic markers. Guillaumin may have found reassortment of the mating factors because he was using a stable $2 \mathrm{~N}+\mathrm{N}$ strain.

Complete conversion of an entire haploid thallus to a new diploid following a diploid-haploid mating may require a long period of time in $A$. ostoyae. Nuclear migration through hyphae via eroded septa is very slow in Armillaria (approximately $1 \mathrm{~mm} \mathrm{~d}^{-1}$ ) (Korhonen, 1983) compared to migration in other basidiomycetes $\left(3-4 \mathrm{~mm} \mathrm{~h}^{-1}\right)$ (Aylmore \& Todd, 1984). Establishment of a balanced dikaryon in di-mon matings of $S$. commune requires extensive nuclear migration of donor nuclei (Nguyen \& Niederpruem, 1984).

Among basidiomycete fungi, nuclear replacement throughout an entire fungal thallus appears to be unique to Armillaria. A type of nuclear replacement following hyphal fusion has been observed cytologically in other basidiomycetes (Aylmore \& Todd, 1984; Todd \& Aylmore, 1985). Replacement of nuclei is common in selffusions of dikaryotic or monokaryotic hyphae in $S$. commune and Trametes versicolor (Aylmore \& Todd, 1984; Todd \& Aylmore, 1985). In di-mon matings of $T$. versicolor, both nuclei of the dikaryon migrate into a fusion 
cell in the monokaryon and the original nucleus of the monokaryon degenerates (Aylmore \& Todd, 1984). Nuclear division appears normal from this fusion cell and new dikaryotic associations are formed. The nuclear replacement reaction observed in $A$. ostoyae appears to be most similar to that reported for matings between nonoutcrossing and outcrossing monokaryotic strains of Stereum birsutum (Ainsworth et al., 1990). In these crosses, nuclei of non-outcrossing strains unilaterally migrate into the outcrossing strain to form a new heterokaryon. Occasionally, monokaryotic sectors appear in which only non-outcrosser nuclei are found with the mtDNA of the outcrosser, suggesting a replacement reaction (Ainsworth et al., 1990).

The exact mechanism of nuclear replacement in $A$. ostoyae is not known. Since haploid nuclei can reside with diploid nuclei for extended periods of time to form an apparently stable $2 \mathrm{~N}+\mathrm{N}$ state, rapid degeneration of nuclei, as in the self-fusions of $T$. versicolor and $S$. commune, seems unlikely. Alternatively, haploid nuclei may stop dividing mitotically and eventually be lost through dilution. Nuclear replacement in other fungi has been hypothesized as a mechanism to avoid excessive numbers of nuclei in cells that are normally binucleate (Ainsworth et al., 1990). Replacement reactions (as described above) apparently do not occur in basidiomycetes with multinucleate cells, such as S. birsutum (Ainsworth \& Rayner, 1989).

\section{Conclusions}

Laboratory studies of diploid-haploid interactions (Guillaumin, 1986; Rizzo \& Harrington, 1992; this study) indicate several genetic processes that may be potentially important in the biology of Armillaria. Armillaria species are tree pathogens and saprobic wood decomposers that may be disseminated via basidiospores or through vegetative growth of mycelia through soil or susceptible host material (e.g. via root to root contact between trees). Recent field studies indicate that Armillaria may form large clones (up to $50 \mathrm{~m}$ in diameter and many hectares in area) and that mating events appear to be very rare in nature (Korhonen, 1978; Kile, 1983; Smith et al., 1990, 1992: Rizzo \& Harrington, 1993). A nuclear replacement mechanism may serve as a means to preserve the 'genetic territory' (Rayner, 1991) of well-established mycelial individuals. Basidiospores that establish a haploid mycelium in the vicinity of an established diploid mycelium may be susceptible to mycelial fusion and replacement by the diploid. Such nuclear replacements should lead to mitochondrial mosaics and potentially be detectable in field samples by utilizing molecular markers. Mitochondrial mosaics formed due to diploid-haploid nuclear replacement would be difficult, however, to separate from a normal mating event in which bilateral nuclear migration takes place (Smith et al., 1990).

Diploid-haploid interactions that result in a stable $2 \mathrm{~N}+\mathrm{N}$ dikaryon may be as ecologically important as nuclear replacement interactions. Heteroploidy is common in many eukaryotes, including fungi, and may be important in variability among individuals and in cellular differenti- ation (Tolmsoff, 1983). In addition, polyploidy may have long term evolutionary effects, such as increases in genome size (Tolmsoff, 1983). Stable $2 \mathrm{~N}+\mathrm{N}$ mycelial individuals in natural populations of Armillaria may serve as a source of increased variability and allow for many potential genetic combinations during basidiome formation. The effects of the $2 \mathrm{~N}+\mathrm{N}$ state on pathogenicity, host range and competitive saprobic ability of $A$. ostoyae are not known.

\section{ACKNOWLEDGEMENTS}

The support of R. A. Blanchette throughout the project is greatly appreciated. We thank M. L. Smith and J. B. Anderson for providing RFLP probes and for comments on the manuscript. P. T. Gieser provided invaluable technical advice. The help of D. Gieser with preparation of the figures and E. Frieders with microscopy is appreciated. Funds for this study were provided in part by the USDA Forest Service, Pacific Northwest Research Station. Additional support for the first author was provided by a Carolyn Crosby Fellowship, Graduate School, University of Minnesota, and a Mycological Society of America Graduate Fellowship. This paper is based in part on a dissertation submitted by the first author to the Graduate School, University of Minnesota, as part of the requirements for the $\mathrm{PhD}$ degree. This paper is published as contribution no. 20827 of the Minnesota Agricultural Experiment Station.

\section{REFERENCES}

Ainsworth, A. M. \& Rayner, A. D. M. (1989). Hyphal and mycetial responses associated with genetic exchange within and between species of the Basidiomycete genus Stereum. J Gen Microbiol 135, 1643-1659.

Ainsworth, A. M., Rayner, A. D. M., Broxholme, S. J. \& Beeching, J. R. (1990). Occurrence of unilateral genetic transfer and genomic replacement between strains of Stereum birsutum from nonoutcrossing and outcrossing populations. New Phytol 115, 119-128.

Anderson, J. B. \& Ullrich, R. C. (1982). Diploids of Armillaria mellea: synthesis, stability, and mating behavior. Can J Bot 60, 432-439.

Anderson, J. B. \& Yacoob, R. (1984). Benomyl-induced somatic segregation in diploid Armillaria mellea. Pbytopatbology 74, 612-615.

Anderson, J. B., Bailey, S. S. \& Pukkila, P. J. (1989). Variation in ribosomal DNA among biological species of Armillaria, a genus of root-infecting fungi. Evolution 43, 1652-1662.

Aylmore, R. C. \& Todd, N. K. (1984). Hyphal fusion in Coriolus versicolor. In The Ecology and Pbysiology of the Fungal Mycelium, pp. 103-125. Edited by D. H. Jennings \& A. D. M. Rayner. Cambridge: Cambridge University Press.

Buller, A. H. R. (1931). Researches on Fungi, IV, Further Observations on the Coprini together with some Investigations on Social Organization and Sex in the Hymenomycetes. New York: Longmans, Green \& Co.

Casselton, L. A. \& Economou, A. (1985). Dikaryon formation. In Developmental Biology of Higher Fungi, pp. 213-229. Edited by D. Moore, L. A. Casselton, D. A. Wood \& J. C. Frankland. Cambridge: Cambridge University Press.

Coates, D. \& Rayner, A. D. M. (1985). Heterokaryon-homokaryon interactions in Stereum birsutum. Trans Brit Mycol Soc 84, 637-645.

Coates, D., Rayner, A. D. M. \& Boddy, L. (1985). Interactions between mating and somatic compatibility in the basidiomycete Stereum birsutum. New Phytol 99, 473-483. 
Davis, R. W., Thomas, M., Cameron, J., St. John, T. P., Scherer, S. \& Padgett, R. A. (1980). Rapid DNA isolation for enzymatic and hybridization analysis. Methods Enzymol 65, 404-411.

Ellingboe, A. H. \& Raper, J. R. (1962). The Buller phenomenon in Schizophyllum commune: nuclear selection in fully compatible dikaryotic-homokaryotic matings. Am J Bot 49, 454-459.

Guillaumin, J. J. (1986). Contribution à l'étude des Armillaires phytopathogènes, en particulier du groupe Mellea: cycle caryologique, notion d'espèce, role biologique des espèces. Thèse, Univ. Claude Bernard-Lyon I, France.

Guillaumin, J. J., Anderson, J. B. \& Korhonen, K. (1991). Life cycle, interfertility, and biological species. In Armillaria Root Disease, pp. 10-20. Edited by C. G. Shaw \& G. A. Kile. USDA Forest Service Agricultural Handbook no. 691. Washington, DC: US Department of Agriculture.

Harrington, T. C., Worrall, J. J. \& Baker, F. A. (1992). Armillaria. In Methods for Research on Soilborne Phytopathogenic Fungi, pp. 81-85. Edited by L. L. Singleton, J. D. Mihail \& C. Rush. St. Paul, MN: American Phytopathological Society Press.

Heath, I. B. (1987). Fluorescent staining of fungal nuclei. In Zoosporic Fungi in Teacbing and Research, pp. 169-171. Edited by M. S. Fuller \& A. Jaworski. Athens, GA: Southeastern Publishing Corporation.

Hintikka, v. (1973). A note on the polarity of Armillariella mellea. Karstenia 13, 32-39.

Hintz, W. E. A., Anderson, J. B. \& Horgen, P. A. (1988). Nuclear migration and mitochondrial inheritance in the mushroom Agaricus bitorquis. Genetics 119, 35-41.

Kile, G. A. (1983). Identification of genotypes and the clonal development of Armillaria luteobubalina Watling and Kile in eucalypt forests. Aust J Bot 31, 657-671.

Korhonen, K. (1978). Interfertility and clonal size in the Armillariella complex. Karstenia 18, 31-42.

Korhonen, K. (1980). The origin of clamped and clampless basidia in Armillariella ostoyae. Karstenia 20, 23-27.

Korhonen, K. (1983). Observations on nuclear migration and heterokaryotization in Armillaria. Cryptogam Mycol 4, 79-85.

Korhonen, K. \& Hintikka, V. (1974). Cytological evidence for somatic diploidization in dikaryotic cells of Armillariella mellea. Arch Microbiol 95, 187-192.

Larsen, M. J., Banik, M. T. \& Burdsall, H. H., Jr (1992). Clamp connections in North American Armillaria species : occurrence and potential application for delimiting species. Mycologia 84, 214-218.

May, G. \& Taylor, J. W. (1988). Patterns of mating and mitochondrial DNA inheritance in the agaric basidiomycete Coprinus cinereus. Genetics 118, 213-220.
Nguyen, T. T. \& Niederpruem, D. J. (1984). Hyphal interactions in Schizopbyllum commune: the di-mon mating. In The Ecology and Physiology of the Fungal Mycelium, pp. 73-102. Edited by D. H. Jennings \& A. D. M. Rayner. Cambridge: Cambridge University Press.

Rayner, A. D. M. (1991). The challenge of the individualistic mycelium. Mycologia 83, 48-71.

Rizzo, D. M. \& Harrington, T. C. (1992). Nuclear migration in diploid-haploid pairings of Armillaria ostoyae. Mycologia 84, 863-868.

Rizzo, D. M. \& Harrington, T. C. (1993). Delineation and biology of clones of Armillaria ostoyae, A. calvescens and A. gemina. Mycologia 85, 164-174.

Sambrook, J., Fritsch, E. F. \& Maniatis, T. (1989). Molecular Cloning: a Laboratory Manual, 2nd edn. Cold Spring Harbor, NY: Cold Spring Harbor Laboratory.

Smith, M. L. \& Anderson, J. B. (1989). Restriction fragment length polymorphisms in mitochondrial DNAs of Armillaria: identification of North American biological species. Mycol Res 93, $247-256$.

Smith, M. L., Duchesne, L. C., Bruhn, J. N. \& Anderson, J. B. (1990). Mitochondrial genetics in a natural population of the plant pathogen Armillaria. Genetics 126, 575-582.

Smith, M. L., Bruhn, J. N. \& Anderson, J. B. (1992). The fungus Armillaria bulbosa is among the largest and oldest living organisms. Nature 356, 428-431.

Swiezynski, K. M. \& Day, P. R. (1960). Migration of nuclei in Coprinus lagopus. Genet Res 1, 129-139.

Todd, N. K. \& Aylmore, R. C. (1985). Cytology of hyphal interactions and reactions in Schizopbyllum commune. In Developmental Biology of Higher Fungi, pp. 231-248. Edited by D. Moore, L. A. Casselton, D. A. Wood \& J. C. Frankland. Cambridge: Cambridge University Press.

Tolmsoff, W. J. (1983). Heteroploidy as a mechanism of variability among fungi. Annu Rev Phytopathol 21, 317-340.

Tommerup, I. C. \& Broadbent, D. (1975). Nuclear fusion, meiosis and the origin of dikaryotic hyphae in Armillariella mellea. Arch Microbiol 103, 279-282.

Ullrich, R. C. \& Anderson, J. B. (1988). Armillaria mellea, cause of rots in woody species. Adv Plant Pathol 6, 491-499.

Williams, J. G. K., Kubelik, A. R., Livak, K. J., Raflski, J. A. \& Tingey, S. V. (1990). DNA polymorphisms amplified by arbitrary primers are useful as genetic markers. Nucleic Acids Res 18, 6531-6535.

Received 18 November 1993; revised 15 March 1994; accepted 22 March 1994. 